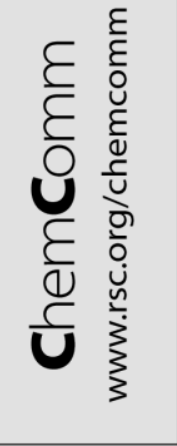

\title{
Self-assembled arrays of zinc oxide nanoparticles from monolayer films of diblock copolymer micelles
}

\author{
Seong Il Yoo, ${ }^{a}$ Byeong-Hyeok Sohn, ${ }^{* b}$ Wang-Cheol Zin, ${ }^{a}$ Sung-Jin An ${ }^{a}$ and Gyu-Chul Yi ${ }^{a}$ \\ a Department of Materials Science and Engineering, Pohang University of Science and Technology, Pohang \\ 790-784, Korea \\ ${ }^{b}$ School of Chemistry, Seoul National University, Seoul 151-747, Korea.E-mail: bhsohn@snu.ac.kr; \\ Fax: +82 2889 1568; Tel: +8228832154
}

Received (in Cambridge, UK) 1st July 2004, Accepted 14th September 2004

First published as an Advance Article on the web 5th November 2004

\begin{abstract}
A hexagonal array of optically active $\mathrm{ZnO}$ nanoparticles was synthesized in situ on the solid substrate by utilizing a singlelayered film of diblock copolymer micelles as a nanostructured template.
\end{abstract}

During the last decade, research on semiconductor nanoparticles has been a wide and interdisciplinary field of science to elucidate and utilize their novel material properties. ${ }^{1}$ Zinc oxide, a wideband-gap semiconductor oxide, is a very fascinating material due to its large exciton binding energy and bond strength, ${ }^{2,3}$ which make it applicable for a blue or ultraviolet optical device. ${ }^{2-4}$

Nanoparticles of zinc oxide can be effectively synthesized in aqueous or organic solutions. Colloidal synthetic routes for $\mathrm{ZnO}$ nanoparticles usually involve the reaction of $\mathrm{Zn}^{2+}$ salts in basic solutions. ${ }^{5-7}$ For their applications, however, controlled deposition of $\mathrm{ZnO}$ nanoparticles from solutions to solid substrates is necessary. To place nanoparticles on a substrate in a specific arrangement, templates have been utilized, which can be lithographically fabricated or self-assembled. ${ }^{8-14}$ In the case of self-assembled templates, a periodic nanostructure of diblock copolymers or their micelles was successfully employed to arrange nanoparticles with a considerable stability. ${ }^{10-14}$ For example, the nanometre-sized micelles of diblock copolymers in a selective solvent for one of the blocks were transferred onto silicon wafers to form a hexagonally ordered monolayer film, which served as a structured template to direct the spatial location of nanoparticles. ${ }^{10-14}$ In addition, an ordered array of metal or oxide nanoparticles was directly synthesized by employing plasma treatments as a successful method of oxidation or reduction of precursors of nanoparticles as well as removal of copolymer templates. Möller and coworkers demonstrated arrays of gold nanoparticles on various substrates with a combination of diblock copolymer micelles and plasma treatments. ${ }^{11}$ Similarly, we reported an array of iron oxide nanoparticles surrounded by gold nanoparticles from a monolayer film of diblock copolymer micelles with subsequent exposure to oxygen plasma. ${ }^{13}$

The fabricated arrays of nanoparticles from diblock copolymer micelles, however, were applied mostly to passive applications such as an etching resistant mask. As an active nanopattern, an array of cobalt nanoparticles was recently synthesized from diblock copolymer micelles although magnetic properties of the array were not reported. ${ }^{12}$ In this communication, we demonstrate instant synthesis of optically active $\mathrm{ZnO}$ nanoparticles in a hexagonal order from a single-layered film of diblock copolymer micelles with oxygen plasma treatment. The near-band-edge emission was observed for the array of $\mathrm{ZnO}$ nanoparticles.

For a monolayer film of diblock copolymer micelles, polystyrene-block-poly(4-vinylpyridine), PS-PVP $\left(M_{\mathrm{n}}{ }^{\mathrm{PS}}=47.6 \mathrm{~kg} \mathrm{~mol}^{-1}\right.$, $M_{\mathrm{n}}^{\mathrm{PVP}}=20.4 \mathrm{~kg} \mathrm{~mol}^{-1}$, polydispersity index $\left.=1.14\right)$ was dissolved in toluene and stirred for $3 \mathrm{~h}$ at room temperature, then stirred for an additional $2 \mathrm{~h}$ at $70{ }^{\circ} \mathrm{C}$ to yield a $0.5 \mathrm{wt} \%$ toluene solution. Because toluene is a selective solvent for the PS block, spherical micelles of a PS corona and a PVP core were formed at this concentration. ${ }^{10-13} \mathrm{~A}$ variety of metal salts, as a precursor of nanoparticles, can be selectively loaded into the PVP core. ${ }^{10}$ Thus,
$\mathrm{ZnCl}_{2}$ was added to the PS-PVP micellar solution (molar ratio of $\mathrm{ZnCl}_{2}: \mathrm{VP}=0.5$ ), then the mixed solution was stirred for at least $24 \mathrm{~h}$ for complete loading of $\mathrm{ZnCl}_{2}$ into the PVP core. From the PS-PVP micellar solution with $\mathrm{ZnCl}_{2}$, a monolayer film of the micelles in a short-ranged hexagonal order was spin-coated typically at $2000 \mathrm{rpm}$ on silicon wafers, freshly cleaved mica, or $\mathrm{Al}_{2} \mathrm{O}_{3}$ (0001) substrates, as described in our previous reports. ${ }^{13}$

To fabricate an array of $\mathrm{ZnO}$ nanoparticles, a film of hexagonally ordered PS-PVP micelles containing $\mathrm{ZnCl}_{2}$ was exposed to oxygen plasma $\left(100 \mathrm{~W}, c a .2 .0 \times 10^{-2}\right.$ Torr $)$ for $10 \mathrm{~min}$. For transmission electron microscopy (TEM) analysis, TEM-grid-sized silicon substrates having a $30 \mathrm{~nm}$ thick silicon nitride membrane window were used. ${ }^{14}$
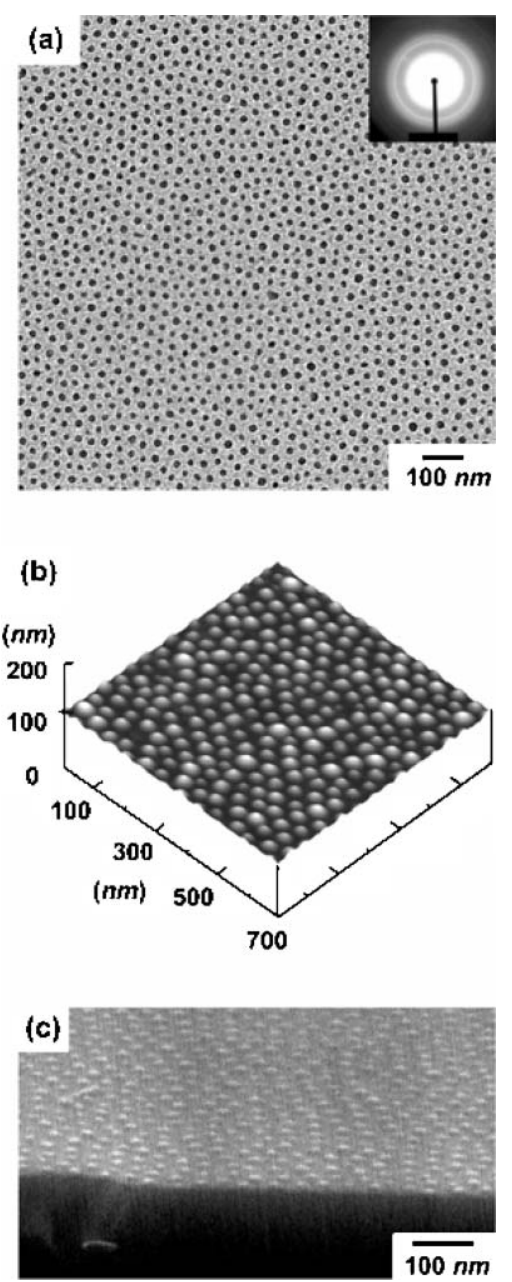

Fig. 1 Self-assembled array of $\mathrm{ZnO}$ nanoparticles in hexagonal order: (a) TEM image; (b) AFM image; (c) FE-SEM image in tilt view. The inset in the TEM image is a selected-area electron diffraction pattern of $\mathrm{ZnO}$ nanoparticles. 


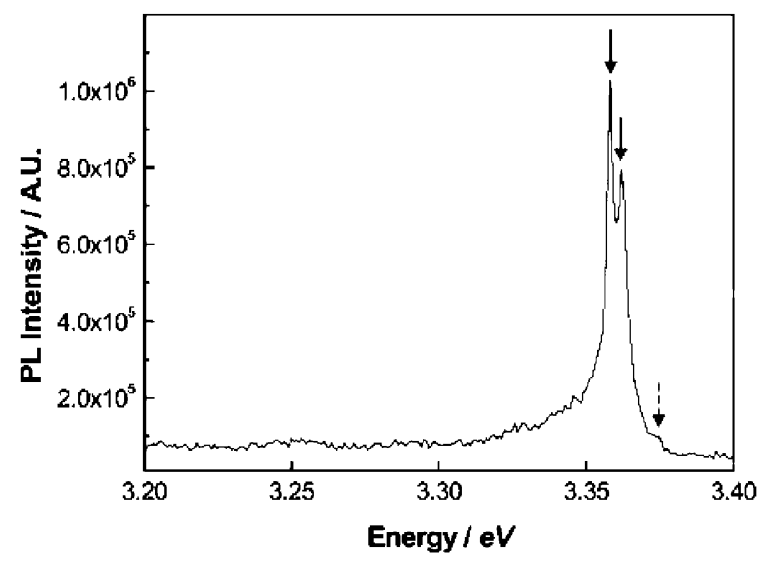

Fig. 2 PL spectrum of a hexagonal array of $\mathrm{ZnO}$ nanoparticles measured at $10 \mathrm{~K}$.

Fig. 1(a) is a TEM image of the synthesized array of $\mathrm{ZnO}$ nanoparticles. The short-range hexagonal arrangement of $\mathrm{ZnO}$ nanoparticles was successfully fabricated from a single layer of PSPVP micelles containing $\mathrm{ZnCl}_{2}$ with the preservation of the two dimensional order of the micelles. The lateral periodicity $(36.0 \mathrm{~nm}$ in average) of $\mathrm{ZnO}$ nanoparticles was the same as that of PS-PVP micelles on the substrate. The TEM image also implies that precursor salts in each core of micelles were oxidized to a single nanoparticle, which did not aggregate even after annealing at $700{ }^{\circ} \mathrm{C}$ for $2 \mathrm{~h}$ in an oxygen atmosphere to improve their crystallinity. The average diameter of $\mathrm{ZnO}$ nanoparticles was $16.0 \mathrm{~nm}$ and smaller than that of the PVP core due to removal of the PVP block by plasma treatment. The wurtzite crystalline structure of $\mathrm{ZnO}$ nanoparticles was verified by the selected-area electron diffraction pattern shown in the inset of Fig. 1(a). In addition, X-ray photoelectron spectroscopy results (not shown) confirmed the complete removal of PS-PVP micelles by the disappearance of the whole carbon peak after oxygen plasma treatment. In topographical images of $\mathrm{ZnO}$ nanoparticles by atomic force microscopy (AFM) in tapping mode (Fig. 1(b)) and field-emission scanning electron microscopy (FE-SEM) in tilt view (Fig. 1(c)), each $\mathrm{ZnO}$ nanoparticle appeared as a hemisphere $c a$. $8.0 \mathrm{~nm}$ in height, which was not much changed after annealing. Thus, synthesis of pure $\mathrm{ZnO}$ nanoparticles and their arrangement in hexagonal order on the solid substrate were simultaneously achieved from single-layered films of PS-PVP copolymer micelles.

To characterize the optical properties of $\mathrm{ZnO}$ nanoparticle arrays, we performed photoluminescence (PL) measurements. As an excitation source for the PL experiment, a He-Cd laser (325 nm) was employed. Fig. 2 shows the low-temperature PL spectrum of $\mathrm{ZnO}$ nanoparticle arrays fabricated on the $\mathrm{Al}_{2} \mathrm{O}_{3}(0001)$ substrate. The spectrum of the annealed array was not much altered, although it was more reproducible compared with that of the nonannealed one. In the PL spectrum, the dominant peaks at 3.358 and $3.362 \mathrm{eV}$, pointed out by two solid arrows in the figure, can be cautiously assigned to neutral donor bound exciton transitions
$\left(\mathrm{D}^{0} \mathrm{X}\right)$ and their excited states. The separation of the bound exciton peaks has been previously observed for bulk $\mathrm{ZnO}$ at 3.357, 3.361, 3.364 and $3.366 \mathrm{eV} .^{15} \mathrm{In}$ addition, the shoulder at $3.375 \mathrm{eV}$, indicated by the dashed arrow in the figure, is probably attributed to a transition from a free exciton (EX) since a similar peak was also observed in singly crystalline $\mathrm{ZnO}^{2-4,15}$ However, quantum confinement effects in the $\mathrm{ZnO}$ nanoparticle array were not observed, presumably because of the relatively large diameter of the nanoparticle. ${ }^{5-7}$

In conclusion, we successfully demonstrated the synthesis of photoluminescent $\mathrm{ZnO}$ nanoparticles in an ordered array on the solid substrate conserving the dimensional order of PS-PVP diblock copolymer micelles. Thus, the array of optically active nanoparticles was directly fabricated on the substrate with a single synthetic step, instead of separated procedures for the synthesis and deposition of nanoparticles. The methodology presented here can be applicable to direct fabrication of various functional arrays with a suitable choice of nanoparticles such as magnetic iron oxide.

This work was supported by the National Program for Nanostructured Materials Technology of the Ministry of Science and Technology as one of the 21st Century Frontier Programs.

\section{Notes and references}

1 A. P. Alivisatos, Science, 1996, 271, 933.

2 W. Y. Liang and A. D. Yoffe, Phys. Rev. Lett., 1968, 20, 59; J. M. Hvam, Solid State Commun., 1978, 26, 987.

3 R. F. Service, Science, 1997, 276, 895; M. H. Huang, S. Mao, H. Feick, H. Yan, Y. Wu, H. Kind, E. Weber, R. Russo and P. Yang, Science, 2001, 292, 1897.

4 S. W. Jung, W. I. Park, H. D. Cheong, G.-C. Yi, H. M. Jang, S. Hong and T. Joo, Appl. Phys. Lett., 2002, 80, 1924; W. I. Park, Y. H. Jun, S. W. Jung and G.-C. Yi, Appl. Phys. Lett., 2003, 82, 964; W. I. Park and G.-C. Yi, Adv. Mater., 2004, 16, 87.

5 L. Spanhel and M. A. Anderson, J. Am. Chem. Soc., 1991, 113, 2826.

6 U. Koch, A. Fojtic, H. Weller and A. Henglein, Chem. Phys. Lett., 1985, 122, 507.

7 D. W. Bahnemann, C. Kormann and M. R. Hoffmann, J. Phys. Chem., 1987, 91, 3789.

8 J. Tien, A. Terfort and G. M. Whitesides, Langmuir, 1997, 13, 5349; H. Zheng, I. Lee, M. F. Rubner and P. T. Hammond, Adv. Mater., 2002, 14, 569.

9 Q. Guo, X. Teng, S. Rahman and H. Yang, J. Am. Chem. Soc., 2003, 125, 630; F. Hua, T. Cui and Y. Lvov, Langmuir, 2002, 18, 6712; Y. Yin and Y. Xia, Adv. Mater., 2001, 13, 267.

10 S. Förster and M. Antonietti, Adv. Mater., 1998, 10, 195.

11 R. Glass, M. Möller and J. P. Spatz, Nanotechnology, 2003, 14, 1153.

12 H.-G. Boyen, G. Kästle, K. Zürn, T. Herzog, F. Weigl, P. Ziemann, O. Mayer, C. Jerome, M. Möller, J. P. Spatz, M. G. Garnier and P. Oelhafen, Adv. Funct. Mater., 2003, 13, 359.

13 B. H. Sohn, S. I. Yoo, B. W. Seo, S. H. Yun and S. M. Park, J. Am. Chem. Soc., 2001, 123, 12734; B. H. Sohn, J. M. Choi, S. I. Yoo, S. H. Yun, W.-C. Zin, J. C. Jung, M. Kanehara, T. Hirata and T. Teranishi, J. Am. Chem. Soc., 2003, 125, 6368.

14 Y. Boontongkong and R. E. Cohen, Macromolecules, 2002, 35, 3647.

15 D. C. Reynolds, D. C. Look, B. Jogai, C. W. Litton, T. C. Collins, W. Harsch and G. Cantwell, Phys. Rev. B, 1998, 57, 12151. 